\title{
Book report \\ Teach a man to fish and you feed him for a lifetime: physics, pharmacology and physiology for anaesthetists
}

Roland CE Francis, Willehad Boemke and Claudia D Spies

Department of Anaesthesiology and Intensive Care Medicine, Charité-Universitätsmedizin Berlin, Campus Virchow-Klinikum and Campus Charité Mitte, Augustenburger Platz 1, D-13353 Berlin, Germany

Corresponding author: Roland CE Francis, Roland.francis@charite.de

Published: 30 May 2008

Critical Care 2008, 12:303 (doi:10.1186/cc6901)

This article is online at http://ccforum.com/content/12/3/303

(c) 2008 BioMed Central Ltd

Cross M, Plunkett E: Physics, Pharmacology and Physiology for Anaesthetists - Key Concepts for the FRCA. 1st edition. Cambridge: Cambridge University Press; 2008, 248 pp. ISBN: 9780521700443 (paperback)



The sheer depth and breadth of knowledge required for the Fellow of the Royal College of Anaesthetists examinations in anaesthesia is compelling. This is particularly true with regards to the basic science components with which you have to be familiar during a challenging viva or multiple choice question examination.

In their book Physics, Pharmacology and Physiology for Anaesthetists, specialist registrars in anaesthetics Matthew Cross and Emma Plunkett provide key concepts, essential knowledge and the deductive reasoning you need to tackle the trickiest basic science questions.

This book is a 'one-of-a-kind' collection of more than 180 precise, clear, and well-labelled diagrams relating to fundamental principles in anaesthesia with well structured, step-bystep explanations. The book aims to leave the reader with a clear understanding of the main point of the diagram and enables him or her to explain the key illustrations, definitions, and derivations to others.

With its manageable size and straightforward syntax, this book is an excellent reference point for virtually all relevant graphs, definitions, and equations relating to the basic science of our speciality. After a general introduction to the method for drawing a curve, how to make definitions and how to derive an equation correctly, the book makes the reader recapitulate some essential mathematical principles (such as logarithms, nonlinearity or SI units, and so on) as well as physical principles (such as the gas laws, osmosis, diffusion, or the Doppler effect, and so on).

As the reader moves on he or she will be guided through pharmacological principles, pharmacodynamics, pharmacokinetics, respiratory, cardiovascular, renal and neurophysio- logy, as well as basic statistical principles used in experimental science and clinical trials.

Physics, Pharmacology and Physiology for Anaesthetists is not intended to be an all-inclusive textbook of anaesthesia, but rather is a useful companion to other books that allow an even deeper insight into the subject matter.

The book has been tuned for those studying for the primary Fellow of the Royal College of Anaesthetists examination but is worthwhile reading for a far greater audience. Specialists in anaesthesia will find it a quick and easy to read guide, to recapitulate the once-learnt but almost forgotten facts and principles depicted here as a concise compilation.

The comprehensive guide provokes the lively impression that anaesthesia consists in large part of the practical application of physical, pharmacological, and physiological principles, and the book shall encourage us to translate this knowledge into our daily routine.

Those who digest the contents of this book will be taught how to approach and explain the basic science they hitherto ignored or feared to be asked about.

'Give a man a fish, and you feed him for a day; teach a man to fish, and you feed him for a lifetime' (Chinese proverb).

\section{Competing interests}

The authors declare that they have no competing interests. 